\title{
A NONLOCAL FRACTIONAL HELMHOLTZ EQUATION
}

\section{Mokhtar Kirane, Batirkhan Kh. Turmetov And Berikbol T. TorebeK}

Abstract. In this paper we study some boundary value problems for a fractional analogue of second order elliptic equation with an involution perturbation in a rectangular domain. Theorems on existence and uniqueness of a solution of the considered problems are proved by spectral method.

Mathematics subject classification (2010): 35R30, 35K05, 35K20.

Keywords and phrases: Caputo operator, Helmholtz equation, involution, fractional differential equation, Mittag-Leffer function, boundary value problem.

\section{REFERENCES}

[1] A. A. Kilbas, H. M. Srivastava, And J. J. Trujillo, Theory and Applications of Fractional Differential Equations, Elsevier, North-Holland, Mathematics studies, 2006.

[2] T. Carleman, Sur la théorie des équations intégrales et ses applications, Verhandl. des internat. Mathem. Kongr. Zurich I, (1932) 138-151.

[3] A. A. ANDREEV, AND I. P. Shindin, On the well-posedness of boundary value problems for a partial differential equation with deviating argument, Analytical methods in the theory of differential and integral equations, Kuybyshev, (1987), 3-6, (Russian).

[4] M. S. BuRluts KAYA, AND A. P. KHROMOV, Initial-boundary value problems for first-order hyperbolic equations with involution, Doklady Mathematics, (2011) 84: 3, 783-786.

[5] B. KH. Turmetov, And B. T. TOREBEK, On solvability of some boundary value problems for a fractional analogue of the Helmholtz equation, New York Journal of Mathematics, (2014) 20: 2014, 1237-1251.

[6] B. Kh. Turmetov, B. T. Torebek, And Sh. Ontuganova, Some problems for fractional analogue of Laplace equation, International Journal of Pure and Applied Mathematics, (2014) 94: 4, 525-532.

[7] O. KH. Masaeva, Dirichlet Problem for the Generalized Laplace Equation with the Caputo Derivative, Differential Equations, (2012) 48: 3, 449-454.

[8] M. Dalla Riva, And S. YAKUBOVICH, On a Riemann-Liouville fractional analog of the Laplace operator with positive energy, Integral Transforms and Special Functions, (2012) 23: 4, 277-295.

[9] A. M. NAKhusheV, On mathematical and information technologies for modeling and control of regional development, Dokl. Adygsk. (Cherkessk.) Mezhdunar. Akad. Nauk., (2007) 9: 1, 128-137.

[10] A. M. Nakhushev, Fractional Calculus and Its Applications, Fizmatlit, Moscow, 2003 (in Russian).

[11] M. A. NAImark, Linear Differential Operators, Part II, Ungar, New York, 1968.

[12] E. I. MoISEEV, On the basis property of systems of sines and cosines, Doklady AN SSSR, (1984) 275: 4, 794-798.

[13] V. A. IL'In, And E. G. Poznyak, Foundations of Mathematical Analysis, 2, Fizmatlit, Moscow, 2002. (Russian). 